\title{
Flood of applicants delays EC training grants
}

Munich. A new European Communities (EC) programme intended to promote mobility for research workers within Europe is again being criticized. Overwhelmed by the number of applications, EC officials decided last week to defer processing them, annoying researchers who say they were given an unreasonably short deadline to submit very complicated proposals.

The Human Capital and Mobility Programme has confused and frustrated scientists since its launch earlier this summer (see Nature 358, 98; 1992). The ECU488 million (US\$710 million) programme is an ambitious attempt to make European science as cohesive and mobile as US science. Most of the money goes to transnational postdoctoral fellowships; 45 per cent of it to individual host institutions offering postdoctoral projects to foreign EC scientists and 40 per cent to networks.

The networks programme has attracted particular criticism. To qualify, researchers must establish links with at least five research laboratories in at least three EC countries. When the early August submission date for applications was finally announced in July, applicants complained that they needed more time. The EC justified its haste by saying that the money would be lost if not allocated this year and that several months would be required for processing.

Despite the complexities, more than 3,000 applications were received and queues ringed the Brussels-based offices on the closing date. The strictness of the deadline was relaxed only for applications from Portugal; they were flown to Brussels by courier on deadline but were lost by the airline and arrived three days late.
The EC, whose support system was capable of handling as many as 500 applications, realized it would not be able to cope with the unexpectedly heavy load. It decided to defer processing of network research project applications and to concentrate instead on the identification of host institutes. Most of these decisions have now been made.

Although the programme's management committees do not meet until November, a spokesman for the EC says that it may still have time to allocate all the money. In any case, the August deadline is not the only opportunity for scientists to receive Human Mobility funds. Unlike most other EC programmes, there is a rolling deadline for applications until 1994. Next year the EC will award grants three times, in March, June and November, from a budget of ECU260 million.

\section{Newton statue under fire}

London. A 12-foot-high bronze statue of Sir Isaac Newton commissioned for the forecourt of the British Library's new headquarters under construction in London has caused a row between the library and scientists. The statue, seen as a maquette below, is an interpretation by Sir Eduardo Paolozzi of a woodcut by the eighteenth-century mystic William Blake, right.

As chronicled in The Times, the first salvo was a complaint by Blake enthusiasts that the artist's vision had been misrepresented. Their letters drew a response from the building's architect, Colin St John Wilson, who said that Blake's view of Newton and his disdain for scientific obsession with the measurable was retained in the

\section{IMAGE UNAVAILABLE FOR COPYRIGHT REASONS}

sculpture. "This equivocal attitude to the values of science is shared by many eminent scientists as well as laymen", Wilson wrote. A few days later, Paolozzi defended his interpretation.

Wilson's comment has infuriated scientists such as Mansel Davies, emeritus professor of chemistry at the University of Wales, Aberystwyth, who feel that such a strong anti-scientific motif is inappropriate for a building that unites for the first time the library's science and humanities collections. "It represents an antagonism to the mathematical basis of science that the Council of the British Library has accepted without question," he says.

The statue, expected to cost $£ 175,000$, is not yet cast. The debate continues.

Ian Mundell 